\title{
Rnai Induced Wing Modification in Leon Mutant Drosophila: A Developmental Analysis
}

\author{
${ }^{1}$ Sandeep Satapathy and ${ }^{2}$ Cheng Ting Chien \\ ${ }^{1,2}$ Department of Neurosciences, Institute of Molecular Biology (IMB), Academia Sinica, R.O.C, Taiwan \\ ${ }^{2}$ Department of Biological Sciences, Indian Institute of Science Education and Research, Bhopal, India
}

Received 2013-09-04; Revised 2013-10-02; Accepted 2013-10-23

\begin{abstract}
The precision of growth of an animal is meticulously regulated by extrinsic and intrinsic factors, with focus on maintenance of organismal homeostasis. The clue to change in physiology or metabolism of an organism, at times can be derived from the changes in phenotypes. In the Drosophila melanogaster model system, GAL 4-overexpressed RNAi driver males (Mini-White Marker), targeted against specific genes, when crossed with Leon mutant (19-2/TM6B) females, yield progeny of different wing types. Different RNAi lines expressing the phenotypes in a gradient of sodden, mid to normal; explains the varying severity of the wing phenotypes. The comparison of flies co-expressed RNAi and Leon mutant with wild type or Leon mutant females; show changes in wing phenotype; in terms of wing venation, Anterior Cortical Vein (ACV) position, Posterior Cortical Vein (PCV) position, bristles on the wing margins and the inter-segmental distance. There is a distinct evidence of both rescue and deterioration phenotype observed at various levels, with the varying levels of RNAi expression in sodden, mid and normal type. A correlational study of these modified wing phenotypes to the physiological and metabolic functionalities; reveals the expression of most of these genes targeted by RNAi, mainly in the brain, heart, thoracic-abdominal ganglion, salivary gland, ovary and testis. Therefore, it can be hypothesized that the Leon mutant can be correlated with the RNAi.
\end{abstract}

Keywords: Leon Mutant, Hedgehog, Wing Imaginal Disc, Crossveins, Segmental Distance, RNAi, Gal4 ms-1096

\section{INTRODUCTION}

In Drosophila melanogaster, the finest genetic toolbox and the feasibility of use of balancer chromosomes, makes it viable for use as an efficient model system for study of genetic and molecular mechanisms associated with development The central importance of body size and shape in evolutionary biology has been further established by distinct external wing phenotypes. The patterning of wing veins, bristles and the shape of the wing, eventually attempt to decipher the molecular and chemical intricacies of sequential development of organism. Leon, the protein of interest is involved in dendritic amortization shortening in neurons and also higher punctual formation, enabling in faster short-range neuron impulse transmission.
The wing, being one of the distinctly viewed phenotype, is an ectodermal structure with well-defined compartmentalization of the wing contents and portions into two distinct groups of boundary classifications; one being anterior-posterior and the other being dorsal-ventral (Acheson et al., 1998; Ashburner, 1998; Babor et al., 1983). The dorsal and ventral epithelial sheets are considered to superimpose on each other, to form what we see as an ectodermal wing blade in its mature form. The mature wing blade is an outcome of fate decision of different group of cells present in the larval imaginaldisc. The final outcome however is seen at the end of 4-5 days After Pupariation (AP). Several researches have proved the effect of natural variation on wing development and also the studied the effect of wing patterning in several Corresponding Author: Sandeep Satapathy, Department of Neurosciences, Institute of Molecular Biology (IMB), Academia Sinica, R.O.C, Taiwan Tel: 07898664419 
Drosophila mutant lines. Although the aerodynamics associated with the wing blades in insects and smaller organisms stands out to be clearly understood, but the consequential effect of variation on wing morphology is still under research. The changing environmental factors, have also added to the possibility of the cross talk of several variation directing factors, which might lead to more distinct and unique change of wing phenotypes. The change being probably, either in benefit or harm to the organism. For the changes in wing shape and morphology, the predominant form of selection is either directional or optimizing considering a relatively wider time period (Mathe and Klaczko, 1999). The precise consensus of these environmental factors and the reception at the organismal level has been consensused by five basic intra-cellular signaling pathways; Hedgehog Signaling (Hh), Bone Morphogenetic Protein (BMP), Epidermal growth factor receptor (Efgr), Wnt and Notch Signaling (Blair, 2007). Optimizing selection on wing shape in natural populations is a very distinct pattern (Weber, 1990). The heritability (in higher degrees) specifically in D.mediopunctata species has also proved genetic flow of information for this optimizing selection criteria (Bryant, 1970).

Vein cells and intervein cells (found between veins) are the two basic group of cells in an adult wing blade determining the venation pattern, with the former being densely packed with higher cuticular pigments than the later one. It is known that the vein cells are the only living cells in a mature wing blade because of the loss of the intervein cells shorty After Pupariation (AP). The other cells of importance being the bristles lining the anterior and posterior wing blade margins with different density of sensory cells packed between the anterior and posterior ends. The bristles in the anterior wing margin has two different kinds of sensory cells making it more dense than the posterior one, which is considered to have one type of sensory cells. The sensory cells exposed at these wing margins actually have different sensory tips for different stimulus. The development and growth of these sensory cells are an important part of the fly metabolism in reception of external signals and get affected by several factors in the due course of development. The most common nomenclature of wing blade includes; five Longitudinal Veins (LVs) ranging from L1-L5 with proximoditsal directionality. Two small rudimentary veins L0 and L6 are found at the proximal end of wing blade. Three Crossveins (CVs) are Anterior Crossvein (ACV) (L3-L4), Posterior Crossvein (PCV) (L4-L5) and humeral cross vein (L0 and wing margin) (Becker et al., 1996; Blair, 2007). The dorsal and ventral differentiation of wings arise out of the differential protrusion of veins on either side of the wing blade w.r.t each other (Fig. 1).

Evolutionary basis of wing vein morphology clearly suggests the possibility of existence of additional veins in primitive wing or the deletion loss of veins w.r.t what existed earlier (Joseph, 2002).

\subsection{Wing Development}

During embryonic development, 20-30 cells form a cluster, which invaginates, from embryonic epithelium with still being adhered to the base with thin stalks. This is the earlier layout of wing development from the wing derived imaginal disc. The differentiation of the initial cluster of cells to a later folded disc epithelium (by the late third instar), is what actually forms the wing blades, hinges and even the thorax of the fly (Blair, 2007) \{initial stages of pupariation, there is an amalgamation of basal and dorsal wing epithelia and the longitudinal proveins forming gap. In contrary to the LV provein pattern in the developmental phase AP, the mature wing shows a narrower vein with fusion of L3 and L4 at the proximal end, forming acv. However, the important question underlying this nomenclature of cells what decides the cell's fate, i.e., either to be a vein cell or an intervein cell and the time of onset and completion of this process of differentiation. This distinctive process actually starts in the late pupariation stage and continues till 4-5 days AP. Thus taking into account several environmental factors and thereby induced variations in the cell fate decision. This decision of cell after is not resultant of invasive or migratory cells during imaginal disc development (Garcia and Merriam, 1971; Celis and Diaz-Benjuma, 2003; Mathe and Klaczko, 1999). The five basic intra-cellular signaling pathways and associated novel components play a pioneer role in positioning of veins in wing blade. These signaling show a predominant wing localized effect. The signaling guided wing venation pattern is classified as; Hedgehog (L3-L4), BMP (L2-L3) (L4-L5), Efgr (Provein and Intervein development), Wnt and Notch signaling (L1L2; L4-L5). The chemical morphogens that involves Hedgehog signaling are actually produced in the posterior compartment of the wing and these further diffuse to the anterior wing blade, where it actively coordinates the Hh signaling (Garcia and Merriam, 1971; Celis and Diaz-Benjuma, 2003). This sorting of the morphogens forms a gradient of these morphogens in the wing at an early stage of adult fly and thus the gradient shifting helps to understand the stage of fly growth and thus positioning of wing veins. The early development of LV proveins is considered to heightened by Efgr signals. 


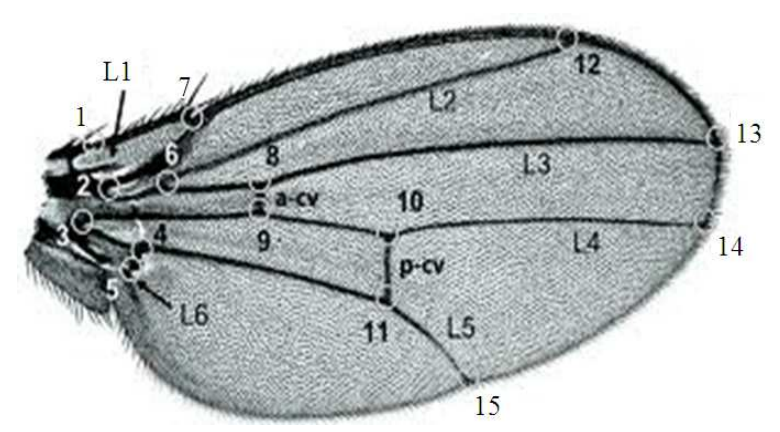

Fig. 1. The Mature Drosophila Wing blade with vein classification

The Decapentaplegic (Dpp) mediated BMP signaling narrows the L2 and L5, without affecting L3-L4 distance and in extreme cases L2 fuses with L3 and L5 (Bryant, 1970). The initial LV proveins being broader gets modified consequently and thus gets refined to the normal narrow veins in the adult wing blade. The LV proveins of the dorsal and ventral side are formed separately on the wing imaginal disc but in a later time of development these get aligned to form the gap between the veins on the dorsal and ventral surfaces in a mature wing blade (Bryant, 1970). The developmental signaling of LVs and CVs are roughly same with exception being the precise positioning along the anterior-posterior part and proximo-distal part (Fig. 2).

The GAL4 or Upstream Activator Sequence (UAS) is an exquisite genetic tool in GAL-mediated overexpression system for Drosophila for targeted gene expression. The use of GAL overexpression has been most commonly for study of mis-expression. However the stereotype has been added with new dimensions for study of gene of interest via enhancers, cellular autonomy of a gene product analysis and analysis of loss of function phenotypes through targeted use of RNAi and dominant negative constructs (Celis and DiazBenjuma, 2003; Gilchrist and Partridge, 2001). ms-1096 GAL4 is a tissue specific GAL4 protein that overexpresses the target protein and thus helps in studying the protein functionalities. The use of GAL4 driven RNAi flies, has shown a temperature dependence mating efficiency with the maturation cycle time period variation. The most ambient temperature for a GAL driven fly is considered to be $28^{\circ} \mathrm{C}$, with minimal activity being noted at $16^{\circ} \mathrm{C}$. Post Translational Gene Silencing (PTGS) or RNAi (interfering RNA) using small interfering RNA (siRNA) or micro RNA (miRNA), is best suited for studying the function of a particular gene by either knocking down or knocking out a particular gene coding for a specific product. The method incorporates binding of a complementary double stranded RNA sequence to the mRNA at particular site and thereby activating the RISC complex (RNAi induced Silencing Complex) which cleaves the mRNA and thus inhibiting the translation of the protein of interest. The difference between siRNA and miRNA is based on the number of nucleotides, being 20 in the former and relatively higher than that in the later and also the fact the former is exogenous and later is endogenous. mi RNA is genomically encoded, non-coding RNA produced particularly in the development phase. These micro RNAs have an incomplete base pairing to target and inhibit the translation of several mRNAs. The RNAi microinjected flies targeted against specific genes, in their downstream, manifest their effect in terms of the wing phenotype changes. The RNAi driven mutation in driver male lines are herited to the progeny by crossing it with Leon mutant female flies and thus progeny with coexpression of RNAi and Leon mutant are generated for wing phenotype modification analysis. The RNAi driver males have RNAi mutation in the first chromosome and balancer chromosomes like Cyo in the second chromosome and the TM6B in the third chromosome. In general, the first three chromosome pairs are of important in studying the Drosophila genetics. Heterogametic organisms have a generally lesser chance of recombination, which is totally absent in male Drosophila. Females however, are active in recombination and thus we use balancers. The balancer chromosome represents a scrambled sequence of chromosome, which limits the chance of homologous recombination in the female $\mathrm{X}$ chromosomes. The presence of the balancers is confirmed by a dominant mutation called Mini White, which coats for red eye color of the fly. Cyo balancers show a distinct curved wing and TM6B causes short-bodied flies with increased number of bristles on the shoulder part. Correlating modified wing phenotypes to the physiological and metabolic functionalities reveals the expression of most of these genes targeted by RNAi, mainly in the brain, heart, thoracic-abdominal ganglion, salivary gland, ovary and testis. Therefore, the clue to change in physiology or metabolism of an organism, at times can be derived from the changes in phenotypes. Even Drosophila, may retain some of the information, as the ectopic veins formed after genetic manipulations, can in some cases mimic aspects of the homologs pattern (Barbancho et al., 1987; Gilchrist and Partridge, 2001; Weber, 1990). 

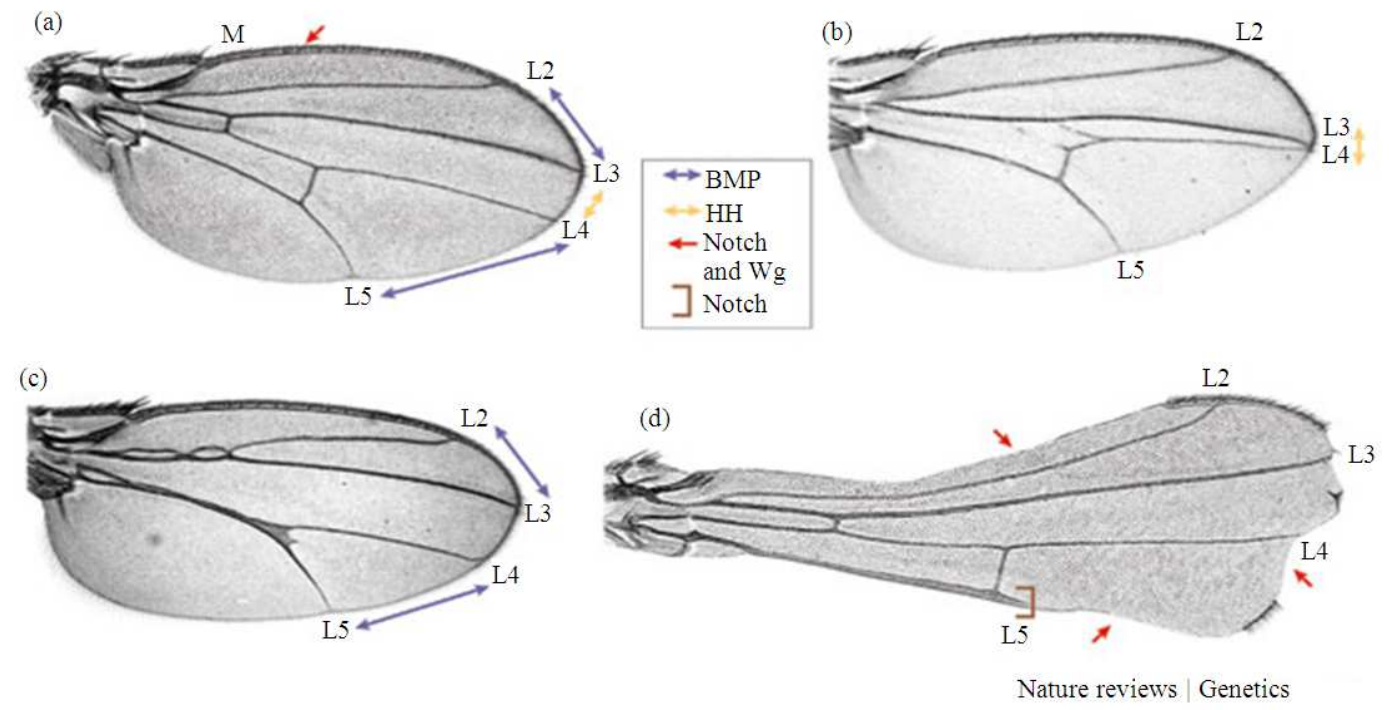

Fig. 2. Intra-Cellular Signaling pathways and the positioning of wing veins (a) Normal wing (b) Hh pathway mutant (c) BMP pathway mutant (d) Notch pathway mutant

\section{MATERIALS AND METHODS}

\subsection{Drosophila Stocks}

The stocks used for analysis are collected from three stock centers; Vienna Drosophila RNAi Center (VDRC), Bloomington RNAi Drosophila stock center (BL) and NIG-Fly. The stocks are described at http://flybase.org unless indicated otherwise. The stocks were also differentially overexpressed with RNAi and the Severity of over expression was arranged chronologically.

\subsection{Crossing of Flies}

The Leon mutant (19-2/TM6B) stocks were incubated at $28^{\circ} \mathrm{C}$ and after 10 days of incubation were checked for the emerging pupae. Three virgin females (white-eyed), marked by whitish fat body, with black dot on their dorsal body, were collected and crossed with two RNAi driver male flies (red-eyed due to mini-white marker). The flies were initially looked regularly for checking health and once they start laying eggs can be collected after ten days. Slides of dissected wings were made with controls as:

- Leon mutant females-W overexpressed by GAL 4 system

- Leon mutant females-W/O GAL 4 overexpression

\subsection{Selection of Flies for Studying Wing Phenotypes}

After 10 days of crossing, the progeny was collected and screened to eliminate all the male flies (white and red eyed) and female flies (white eyed with balancer phenotype like curved wings for cyo and short body with bristles for TM6B). The collected females for final wing dissection were straight-winged, red eyed, less bristles on the shoulder and longer body. Then the collected flies were kept to freeze at $4^{\circ} \mathrm{C}$ for a day.

ms-gal4/ Y; RNAi / Cyo ; + + +

(Male)

$\begin{array}{cc}\mathbf{X} & \\ +/+; & +/+; \quad \text { Leon mutant } 19-2 / \text { TM6B }\end{array}$

\section{(Female)}

Selected flies-

$\checkmark \quad$ ms-gal4; RNAi /+; Leon mutant 19-2/+

Rejected Flies:

ms-gal4; $\quad$ RNAi /+ ; + / TM6B

ms-gal4 ; + / Cyo; Leon mutant 19-2 / +

ms-gal4; +/ Cyo; +/ TM6B

\subsection{Wing Dissection and Microscopy}

The frozen flies were used to cut the wings from the proximal end and the dissected wings were collected in an eppendorf with $100 \mu \mathrm{L}$ of PBST-Triton X buffer and left for mixing on a shaker for an hour. After though washing with PBST buffer the wings were mounted on 
slides using 1:1 solution of Hoyer and Lactic acid (around 1-2 drops). The coverslip was fixed with acetone and later filmed under light microscope and images were analyzed with the control images. The tissue specificity of the gene targeted by RNAi is checked by GFP tagging of the protein with GAL4 (GAL4-GFP-RNAi), which was later analyzed by fluorescence microscopy.

\subsection{Parameterization}

Each of these parameters is equally likely to occur and thus given a score of 1 . These were used to calculate the severity of the effect, if seen any. The size of the wing hasn't been considered as a parameter with a score of one because of the fact that, the size modifications were not equally likely and were observed for very few of the fly lines which showed effect:

- Segmental distance between LCVs

- Anterior Cross vein

- Posterior Cross vein

- Wing notching

- Vein nodes at the proximal and distal ends

- Bristles and serration to form lobe at L5

\subsection{Scoring the Effect}

Percentage of Effect (Rescue / Distortion) $=$
$\frac{\text { No of parameters affected }}{\text { Total possible parameters to be affected }} \times 100$

\section{RESULTS AND DISCUSSION}

Broadly the wing phenotype modifications can be classified into (Fig. 3):

- $\quad$ Rescue (R)-Improved wing architecture in progeny vs. control

- Deteriorated (D)-degraded wing architecture in progeny vs. control

- No Effect (N)-wing architecture same as control

\subsection{Rescue (R)}

The rescue phenotype is an important analysis study in Drosophila genetics, considering the beneficial effects, that can be further extracted of it. However, there is a strict variation in the number of parameters rescued or in other terms the relative degree of development of wing blade in the co-expressed mutant in comparison to the control. A score of $6 / 6$ sets out an extreme rescue event, in which all the parameters considered to be expressed, are actually rescued. A 3/6 rescue symbolizes $50 \%$ rescue and a 1/6 sets out the lower extreme of rescue phenotype, i.e., minimum parameter rescued (Fig. 4). The images seen above show the effect on wing margin bristles is a rare effect seen, where as segmental distance, acv and pcv are most distinctly effected or rescued parts. For a $3 / 6$ score, acv, L4-L5 segmental distance and lobe formation at L5 is recued and thus taking into account three parameters. Similarly the results for all the fly lines were computed.

The ability to resue the wing patterning features in Drosophila is seen to be mostly for a $50 \%$ rescue, i.e., a score of 3/6 (Fig. 5). In general the fly homeostasis allows a $50 \%$ rescue of wing phenotypes. Evolutionarily, this seems top be convincing because of the possibility that the extreme rescue events (score of 5/6 or 6/6) might lead to cross talking of the basic intra-cellular signaling pathways and thereby negatively affecting fly viability. The least favorable rescue is observed to be $5 / 6$ or $83 \%$ rescue meaning the rescue percent 50 , is an threshold in deciding tether the fly favors below $50 \%$ rescue (considering fly system efficiency). But an efficient fly system can actually favor very high degrees of rescue (score of $5 / 65$ or 6/6). The Rescue percentage is also the differentially driven by the RNAi overexpression levels. The gradient of expression may also effect the percentage of rescue.

\subsection{Deterioration (D)}

The deterioration of wing baled induced due to RNAi, is a very common effect observed with the severity of distortion varying with the fly lines depending on the fly system integrity and the RNAi overexpression levels. A 6/6 distortion shows complete loss of wing blade characteristics features and thus marks an extreme with a $1 / 6$ being the lower extreme with one parameter loss, generally being the acv/pcv or the segmental distance variation (Fig. 6). A 3/6 scored fly line had distorted in terms of acv, L4-L5 segmental loss and the lobe at 15 loss with loss of terminal L5 vein at the distal end (Fig. 6). This system was used in classifying the fly lines as per the distortion percentage, a possible answer to the fly machinery efficiency.

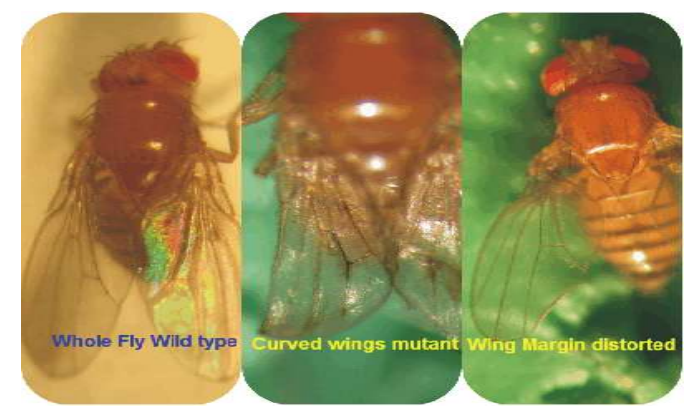

Fig. 3. Whole fly comparison of mutant and control 
Sandeep Satapathy and Cheng Ting Chien / American Journal of Biochemistry and Biotechnology 9 (4): 438-447, 2013

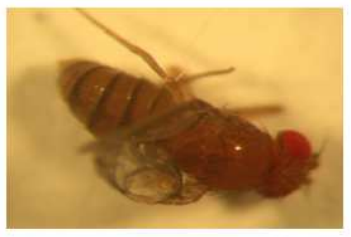

Rescued->
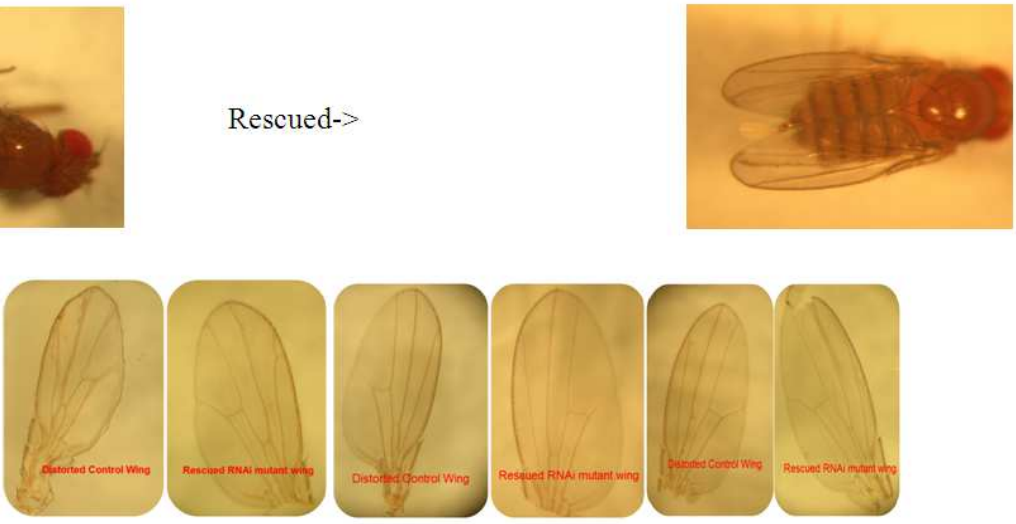

Score-3/6

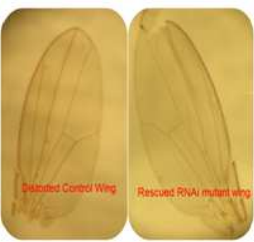

Score-1/6

Fig. 4. Rescued whole fly and wing slides

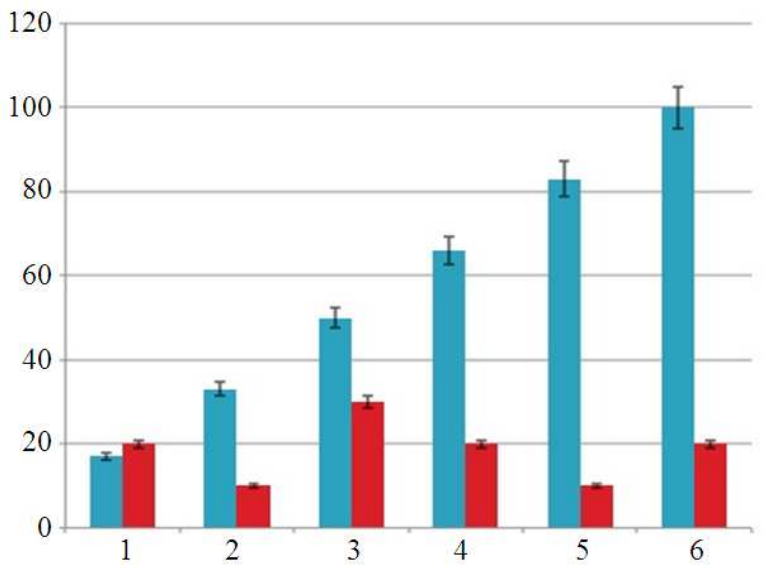

Approximate percentage of rescue $(\%)$

a No of files rescued

Fig. 5. Rescue analysis

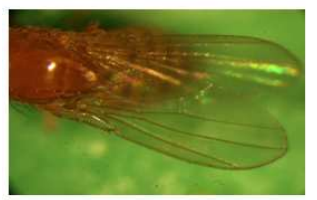

Deteriorated->

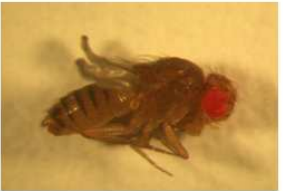

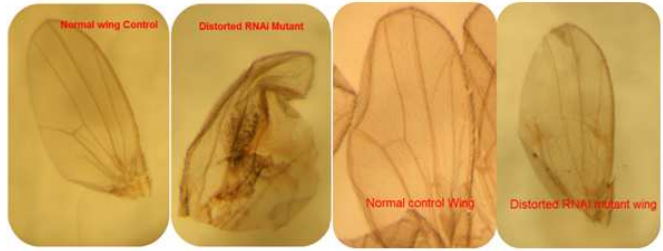

Score-6/6
Score-3/6

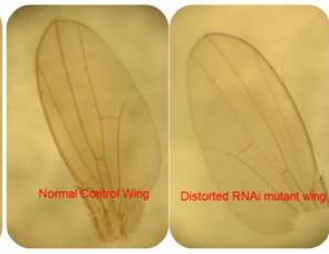

Score- $1 / 6$

Fig. 6. Distorted whole fly and wing slides 
The deterioration phenotype is commonly seen for a single parameter loss, i.e., score of 1/6 (Fig. 7). The general loss being, loss of acv/pcv or segmental distance modifications. Considering the evolution significance the distortion percentage mostly lying at $15 \%$, also signifies the sensitivity of the fly machinery to the negative or deleterious effects of mutation on the physiology. The least favorable deterioration is for a $5 / 6(83 \%)$ or $6 / 6(100 \%)$ deterioration, confirming the earlier suggested possibility of the stricter sensitivity of fly machinery to negative changes of the physiology thereby affecting homeostasis.This distortion possible might have raised out of the difference in RNAi overexpression in the fly lines, but mostly $15 \%$ distortion is what lies in the favorable range of fly homeostasis.

\subsection{Both Rescued and Deteriorated}

A very distinctive effect is the same co expressed fly wing exhibiting both rescue and deterioration phenotypes together (Fig. 8). However, the degree of rescue or distortion is different and mostly the fly lines, which showed this dual effect, had deterioration score outweighing the rescue. The possible factor accounting for such a phenotypic expression roots to the sensitivity of the signaling pathways guiding the positioning of wing patterns. The signaling pathways when simultaneously perceive both rescue and distortion the fly machinery favors deterioration of the wing phenotypes, mostly inhibiting the wing vein proteins in such cases, in an effort to maintain homeostasis:

Rescue (R)-wing notching; Score-1/6

Distorted (D)-acv completely lost, pcv apparently exists, L5 lost, venation distorted; Score-4/6

\subsection{RNAi Gradient and Effects Correlation}

The varying intensity of RNAi overexpression helps us to cross check whether the RNAi is showing desired effect. For the severely expressed RNAi, cases with no effect theoretically should be minimum and some affect either rescue or distortion should dominate and that's marked in the analysis results (Fig. 9). In the severely expressed RNAi rescue phenotypes is most commonly seen whereas it's negligibly less in mid and normally expressed RNAi (Fig. 9). For mid and normally expressed ones there is a significant fly line population showing no effect, which possibly is due to the non specificity of the genes targeted by RNAi, where such genes either show tissue specific expression in reproductive tissues or carcass and are not linked to the wing development from imaginal disc.

\subsection{RNAi-Leon Co Expressed Mutant and Physiological Interference}

The database of the fly lines showing effect has been tabulated to compare and analyze the possible (Table 1).

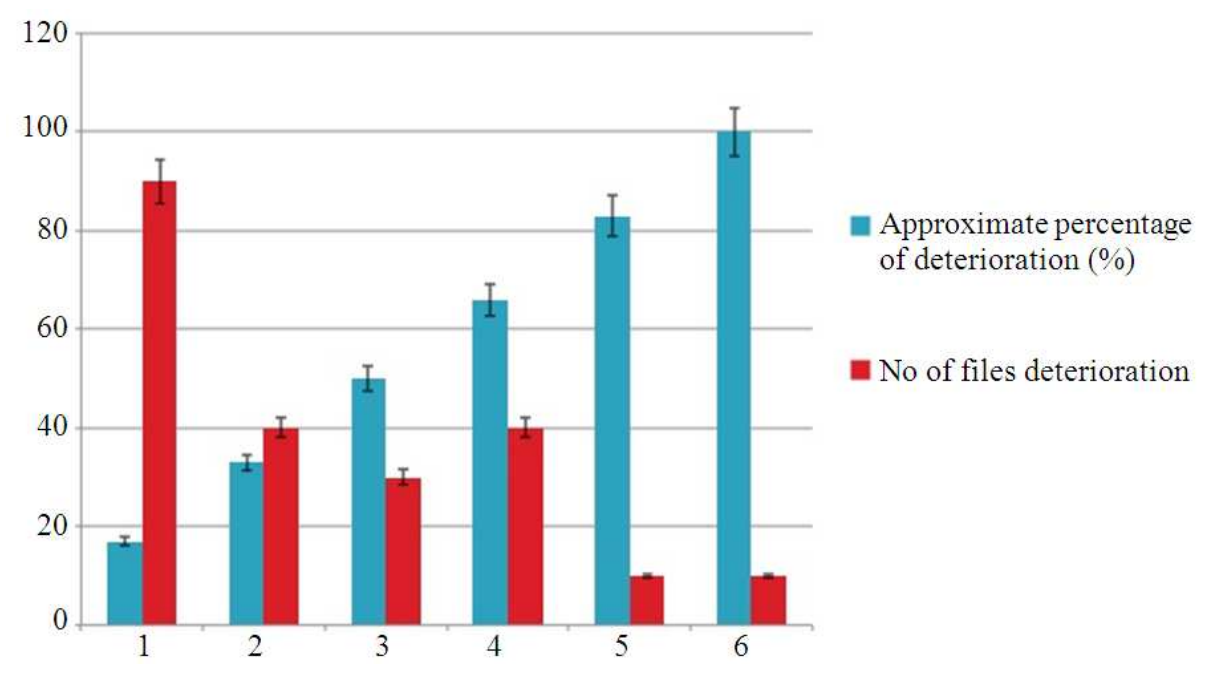

Fig. 7. Deterioration analysis 
Table 1. Database of the fly lines to compare and analyze

\begin{tabular}{|c|c|c|c|c|c|}
\hline $\begin{array}{l}\text { Tube } \\
\text { Label }\end{array}$ & $\begin{array}{l}\text { Targeted } \\
\text { gene }\end{array}$ & $\begin{array}{l}\text { Related gene } \\
\text { and function }\end{array}$ & $\begin{array}{l}\text { Expression in } \\
\text { adult tissue }\end{array}$ & $\begin{array}{l}\text { Observed } \\
\text { phenotype }\end{array}$ & $\begin{array}{l}\text { Physiological/Metabolic } \\
\text { function }\end{array}$ \\
\hline 17260R-1/T6 & CG17260 & $\begin{array}{l}\text { CG17259 aminoacyl } \\
\text { t-RNA synthetase class II) }\end{array}$ & $\begin{array}{l}\text { Testis and male } \\
\text { reproductive tissue }\end{array}$ & $\begin{array}{l}\text { Rescued-Proximal } \\
\text { Wing vein and a } \\
\text { cv restored }\end{array}$ & $\begin{array}{l}\text { Zinc ion binding, Protein } \\
\text { features-RWD Domain. }\end{array}$ \\
\hline 106192/СyO & CG5794 & $\begin{array}{l}\text { at1 (guanyl ribonucloetide } \\
\text { binding.) }\end{array}$ & $\begin{array}{l}\text { Brain, Imaginal } \\
\text { Disc }\end{array}$ & $\begin{array}{l}\text { Rescued-wing } \\
\text { notching lost } \\
\text { Distorted-acv, pcv } \\
\text { and wing vein lost }\end{array}$ & $\begin{array}{l}\text { Ubiquitin thioesterase } \\
\text { activity, regulation of } \\
\text { gene silencing, protein } \\
\text { ubiquitination. }\end{array}$ \\
\hline 100136/СyO & RhoGAP93B & $\begin{array}{l}\text { CG7056 (specific DNA } \\
\text { binding Transcription Factor) }\end{array}$ & $\begin{array}{l}\text { Brain and Thoracic } \\
\text { Abdominal ganglion }\end{array}$ & $\begin{array}{l}\text { Distorted-acv,L3-L4 } \\
\text { distance, proximal vein }\end{array}$ & $\begin{array}{l}\text { Rho-GTPase activity, axon } \\
\text { guidance activity, Myth } 4 \\
\text { domain in proteins. }\end{array}$ \\
\hline 102513/СyO & vito & Scny (Ubiquitin thioesterase) & $\begin{array}{l}\text { Female reproductive } \\
\text { parts }\end{array}$ & Distorted-pcv & $\begin{array}{l}\text { Positive regulation of cell } \\
\text { growth, acts as a } \\
\text { nucleoprotein }\end{array}$ \\
\hline 100708/СyO & $\operatorname{Src} 42 \mathrm{~A}$ & mle (chromatin binding) & CNS, Imaginal DISC & $\begin{array}{l}\text { Rescued-acv, pcv, L4, L5, } \\
\text { L3-L4 distance widened }\end{array}$ & $\begin{array}{l}\text { Protein tyrosine kinase } \\
\text { activity, biogenesis } \\
\text { regulator, cellular } \\
\text { compartmentalization }\end{array}$ \\
\hline 38998/CyO & Gint3 & Sp2637 (asparagine activity) & $\begin{array}{l}\text { Eye, Thoracic } \\
\text { abdominal ganglion }\end{array}$ & $\begin{array}{l}\text { Rescued-acv, pcv, } \\
\text { vein architecture }\end{array}$ & $\begin{array}{l}\text { Protein binding, PUB } \\
\text { domain, PUG domain, } \\
\text { UBX domain. }\end{array}$ \\
\hline $108832 / \mathrm{CyO}$ & ash1 & $\begin{array}{l}\text { CG9330 (ATPase activity, } \\
\text { transporter) }\end{array}$ & Ovary & $\begin{array}{l}\text { Rescued-acv, proximal } \\
\text { wing veins of L3 and L4 }\end{array}$ & $\begin{array}{l}\text { Histone lysine N-methyl } \\
\text { trasferase activity, ssRNA } \\
\text { binding activity }\end{array}$ \\
\hline 101684/CyO & ru, rho3 & - & Brain, Eye, head & $\begin{array}{l}\text { Distorted-L2-L3 narrowed } \\
\text { at proximal end }\end{array}$ & Serine-type peptidase activity \\
\hline 105883/CyO & Rbp1-like & $\begin{array}{l}\text { Tim9a (P-P bond hydrolysis } \\
\text { driven protein) }\end{array}$ & Brain & $\begin{array}{l}\text { Distorted-Notching, acv } \\
\text { lost, vein distorted }\end{array}$ & $\begin{array}{l}\text { Nucleotide binding, nucleic } \\
\text { acid binding, RNA splicing }\end{array}$ \\
\hline $23263 / \mathrm{CyO}$ & DN-Rab14 & & & $\begin{array}{l}\text { Distorted-acv lost, L3-L4 } \\
\text { segment widened }\end{array}$ & \\
\hline 9379R-2/T6 & By & mura (zinc ion binding) & $\begin{array}{l}\text { Crop and salivary } \\
\text { gland }\end{array}$ & Distorted-Wing venation & $\begin{array}{l}\text { Actin binding, wing } \\
\text { morphogenesis }\end{array}$ \\
\hline 100809/CyO & Vap-33-1 & $\begin{array}{l}\text { Lva (actin/microtubule } \\
\text { binding) }\end{array}$ & Brain, Eye, Heart & $\begin{array}{l}\text { Distorted-pcv shifted, } \\
\text { L4-L5 widened }\end{array}$ & $\begin{array}{l}\text { Structural molecule activity, } \\
\text { innate immune response }\end{array}$ \\
\hline 101669/CyO & Hsp27 & $\begin{array}{l}\text { Hsp 23(hypoxia, cold } \\
\text { acclimation) }\end{array}$ & $\begin{array}{l}\text { Malphagian tubules, } \\
\text { Ovary }\end{array}$ & $\begin{array}{l}\text { Distorted-L3-L54 } \\
\text { widened }\end{array}$ & $\begin{array}{l}\text { Protein binding, defense } \\
\text { response }\end{array}$ \\
\hline 11152/CyO & scny & Vito (cell growth regulator) & Brain, eye, head & Distorted-L4-L5 widened & $\begin{array}{l}\text { Ubiquitin thioesterase } \\
\text { activity }\end{array}$ \\
\hline 105534/СyO & Rabex-5 & Scf(topoisomerase activity) & Salivary gland & Distorted-L4-L5 narrowed & Imaginal disc development \\
\hline $5562 \mathrm{R}-3 / \mathrm{CyO}$ & & $\begin{array}{l}\text { eIF6 (translation elongation } \\
\text { factor) }\end{array}$ & $\begin{array}{l}\text { Salivary gland, male } \\
\text { accessory gland }\end{array}$ & $\begin{array}{l}\text { Rescued-acv, pcv, } \\
\text { wing vein restored }\end{array}$ & $\begin{array}{l}\text { Transformation growth factor } \\
\text { beta receptor binding, } \\
\text { neurotransmitter regulator, } \\
\text { NMJs growth }\end{array}$ \\
\hline 105946/CyO & $\mathrm{e}(\mathrm{y}) 3$ & MKP4 (phosphatase activity) & Ovary, Eye & $\begin{array}{l}\text { Distorted-L5,L4-L5 } \\
\text { widened }\end{array}$ & $\begin{array}{l}\text { Chromatin binding, } \\
\text { genesilencing, Imaginal disc } \\
\text { development }\end{array}$ \\
\hline 108814/CyO & TNF (egr) & CG2269 & Eye, brain, heart & Distorted-acv,pcv,L5 & $\begin{array}{l}\text { Protein binding, innate } \\
\text { immunity }\end{array}$ \\
\hline 110618/CyO & MRG15 & CG4338 & Eye, brain, Ovary & Distorted-L4-L5 widened & $\begin{array}{l}\text { Methylated histone binding, } \\
\text { chromatin silencing }\end{array}$ \\
\hline 6637R-2/CyO & 1sn, Vps22 & Eby (spermatid development) & $\begin{array}{l}\text { Head, ovary, eye } \\
\text { Brain }\end{array}$ & Distorted-acv, pcv, veins & $\begin{array}{l}\text { Apoptosis \&notch signalling } \\
\text { regulator }\end{array}$ \\
\hline 3998R-1/CyO & zf30C & $\begin{array}{l}\text { Taf1 } 1 \text { (transcription } \\
\text { factor binding) }\end{array}$ & $\begin{array}{l}\text { Brain, Thoracic } \\
\text { abdominal ganglion }\end{array}$ & Rescued-acv & $\begin{array}{l}\text { Neuron development, ZINC } \\
\text { finger } \mathrm{C} 2 \mathrm{H} 2 \text { domain }\end{array}$ \\
\hline 51977/T6 & fng & CG10589 & $\begin{array}{l}\text { Thoracic abdominal } \\
\text { ganglion }\end{array}$ & $\begin{array}{l}\text { Distorted-pcv, L4-L5 } \\
\text { widened }\end{array}$ & $\begin{array}{l}\text { Single organism } \\
\text { development, biogenesis }\end{array}$ \\
\hline 10079R-1 (II) & EGFR & & $\begin{array}{l}\text { Distorted-L4-L5 } \\
\text { widened }\end{array}$ & & \\
\hline
\end{tabular}




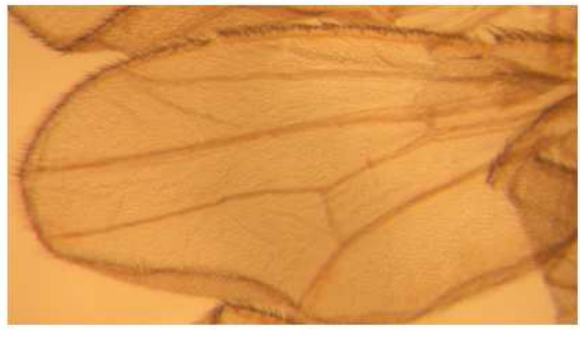

Control

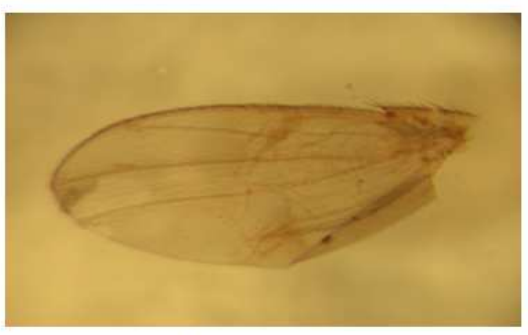

Mutant

Fig. 8. Simultaneous rescue and distortion

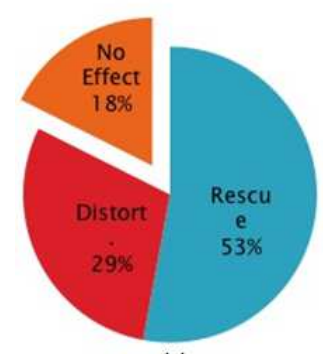

Sodden

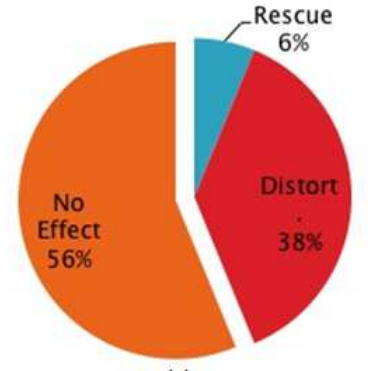

Mid

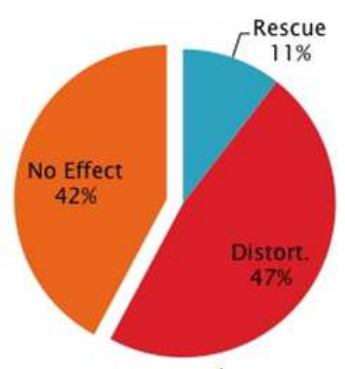

Normal

Fig. 9. RNAi gradient with effect types

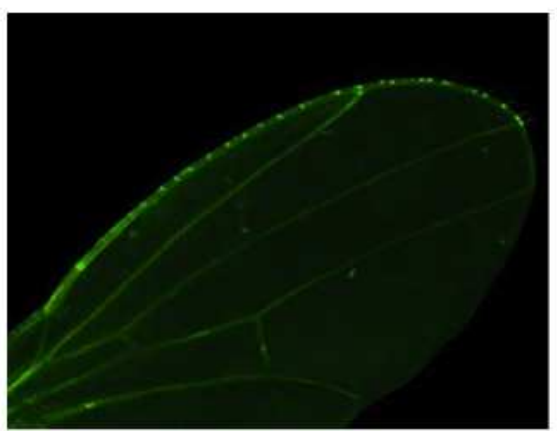

Wing blade

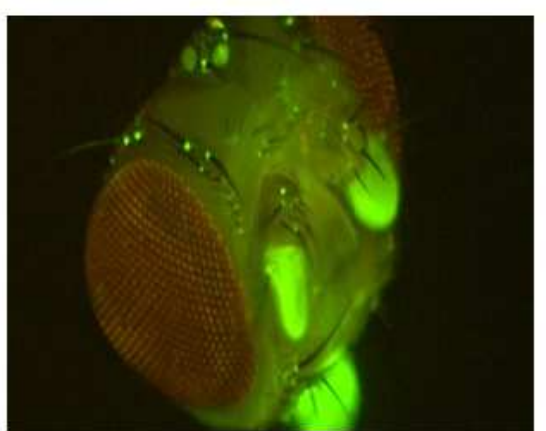

Head/brain

Fig. 10. Mostly RNAi showing effects are localized in wing disc, head or brain

\subsection{Organ/Tissue Localization}

Upon analysis, the most common tissue specific expression is seen in wing disc and brain or head (Fig. 10). The expression was confirmed from the fly base data of fly anatomy of expression at adult stage. The GFP tagged fluorescent expression of these genes targeted showed the most RNAi lines showing effect to be either expressed in brain and head. The expression in ovary, testis, fat body, salivary gland and thoracic abdominal ganglion were tissues which show relatively less expression in cases of fly showing either rescue or distortion effects. Mostly flies showing a distortion effect were involved in neurological functions and in development of sensory organs.

\section{CONCLUSION}

In general, rescue and deterioration phenotypes were seen in flies where genes targeted by RNAi are expressed at higher percentage specifically in wing tissues or the imaginal disc (coding for wing 
development). Most common tissue specific expression in adult fly with change in wing patter is observed in brain, head, imaginal Disc, thoracic abdominal ganglion and eye. The RNAi gradient of overexpression also influenced the phenotypic effect:

- Severely overexpressed RNAi $\rightarrow$ Predominantly Rescue phenotype

- $\quad$ Mid overexpressed RNAi $\rightarrow$ Mostly No effect with few cases of distortion

- Normally Overexpressed RNAi $\rightarrow$ Predominantly Distortion

The further analysis of these phenotypic changes can give an idea of the intracellular signaling pathways specifically targeted by these RNAi fly lines co expressed with Leon mutant. Information on position and morphogens are of prime importance in studying developmental biology. In Drosophila system, there are several diffusible proteins along the anterior-posterior compartments, leading to the nested expression of certain specific genes, which regulate the wing venation and cell positioning. Still even after 15 years of intense research about wing patterning, the scaled presence of morphogens and fate decision of wing disc cells in response to the five basic intracellular signaling pathways still remains not completely understood. However, the stereotyped use of wing pattern analysis in understanding the possible effect on physiology and developmental sequence still holds to be of significance.

\section{ACKNOWLEDGMENT}

I would like to thank Man Wen Chen, Li-Shin and Pei-Fung, for their support and help in completion of this project. Taiwan International Graduate Program (TIGP)International Internship Program 2013 and Institute of Molecular Biology (IMB), Academia Sinica, Taiwan, have funded this project.

\section{REFERENCES}

Acheson, S.K., R.M. Stein and H.S. Swartzwelder, 1998. Impairment of semantic and figural memory by acute ethanol: Age-dependent effects. Alcohol Clin. Exp. Res., 22: 1437-1442. DOI: 10.1111/j.15300277.1998.tb03932.x

Ashburner, M., 1998. Speculations on the subject of alcohol dehydrogenase and its properties in Drosophila and other flies. BioEssays, 20: 949-954. DOI: $\quad 10.1002 /($ SICI)15211878(199811)20:11<949::AID-BIES10>3.0.CO;2-0
Babor, T.F., S. Berglas, J.H. Mendelson, J. Ellingboe and K. Miller, 1983. Alcohol, affect and the disinhibition of verbal behavior. Psychopharmacology, 80: 53-60. DOI: $10.1007 / \mathrm{BF} 00427496$

Barbancho, M., F.J. Sanchez, G. Dorado and M. Pineda, 1987. Relation between tolerance to ethanol and Alcohol Dehydrogenase (ADH) activity in Drosophila melanogaster: Selection, genotype and sex effects. Heredity, 58: 443-450. DOI: 10.1038/hdy.1987.73

Becker, H.C., J.L. Diaz-Granados and C.L. Randall, 1996. Teratogenic actions of ethanol in the mouse: A minireview. Pharmacol. Biochem. Behav., 55: 501-513. DOI: 10.1016/S0091-3057(96)00255-9F

Blair, S., 2007. Wing vein patterning in Drosophila and the Analysis of Intercellular Signaling. Annu. Rev. Cell Dev. Biol., 23: 293-319. DOI: 10.1146/annurev.cellbio.23.090506.123606

Bryant, P.J., 1970. Cell lineage relationships in the imaginal wing disc of Drosophila melanogaster. Dev. Biol., 22: 389-411. DOI: 10.1016/00121606(70)90160-0

Celis, J.F. and F.J. Diaz-Benjuma, 2003. Developmental basis for vein pattern variations in insect wings. Int. J. Dev. Biol., 47: 653-663. PMID: 14756341

Garcia, A.B. and J.R. Merriam, 1971. Parameter of the wing imaginal discs development of Drosophila melanogaster. Dev. Biol., 24: 61-87. DOI: 10.1016/0012-1606(71)90047-9

Gilchrist, A.S. and L. Partridge, 2001. The contrasting genetic architecture of Wing size and shape in Drosophila melanogaster. Heredity, 86: 144-152. DOI: 10.1046/j.1365-2540.2001.00779.x

Joseph, D.B., 2002. Gal4 system in Drosophila: A fly geneticist's Swiss Army knife. Genesis, 34: 1-15. DOI: $10.1002 /$ gene. 10150

Mathe, B.C. and L.B. Klaczko, 1999. Heritability, phenotypic and genetic correlations of size and shape of Drosophila mediopunctata wings. Heredity, 83: 688-696. DOI: $\quad 10.1046 /$ j.13652540.1999.00606.x

Weber, K.E., 1990. Artificial selection on wing allometry in Drosophila melanogaster. Genetics, 126: 975989. PMID: 2127580 